\title{
Seismic behavior of an old masonry building in Vila Real de Santo António, Portugal
}

\author{
J. Ortega \& G. Vasconcelos \\ ISISE, University of Minho, Guimarães, Portugal \\ H. Rodrigues \\ RISCO, School of Technology and Management, Polytechnic Institute of Leiria, Portugal \\ M. Correia \\ CI-ESG, Research Centre, Escola Superior Gallaecia, Portugal
}

\begin{abstract}
Vila Real de Santo António is located in the Algarve region and was erected ex novo at the end of the $18^{\text {th }}$ Century, after the 1755 Lisbon earthquake, following a Pombaline development that showed seismic concern at an urban and architectural level. However, most of the original constructions have been subjected to continuous alterations or even substituted for new ones. The first building built in the town was the Alfândega or Customs House and was selected as a case study because it still preserves most of its original characteristics. It was studied through historical survey, visual inspection and experimental in-situ characterization. As a result, a detailed finite element model was constructed and pushover analyses were carried out to assess its seismic vulnerability. The main goals of the paper are to understand the resisting mechanisms and seismic behavior of the building, as well as to evaluate the influence of structural alterations.
\end{abstract}

\section{INTRODUCTION}

This paper is part of an ongoing research regarding vernacular architecture earthquake preparedness. It has been developed under the framework of the research project 'SEISMIC-V: Vernacular Seismic Culture in Portugal', which focuses on the identification of adequate retrofitting techniques for vernacular buildings empirically developed by local populations to prevent or repair earthquake damage, resulting from a Local Seismic Culture (Correia et al. 2014). Traditional earthquake resistant constructions and techniques arise in seismic prone regions as a reaction to earthquakes because people continuously exposed to seismic hazard had to make construction efforts and develop preventive measures for earthquake mitigation, leading to what was defined by Ferrigni (1990) as Local Seismic Culture.

Vila Real de Santo António was constructed from scratch after the Lisbon 1755 earthquake. As a result, buildings were originally constructed using seismic resistant provisions and the urban plan was also earthquake-inspired, designed in order to protect people in a seismic event. This development was contemporary to the reconstruction of Lisbon and was also enacted by the Marquis of Pombal. Therefore, it shares many similarities and is based on the same ideas and criteria, resulting in a similar urban design in terms of composition and rigorous geometric clarity, as well as in the social and industrial functionality. The Pombaline city plan consists of an extremely regular rectangular grid with one of the long sides placed along the river, organized around a large central square and with four strictly defined distinct architectural types that defined a clear hierarchy at an urban level (Figure 1).
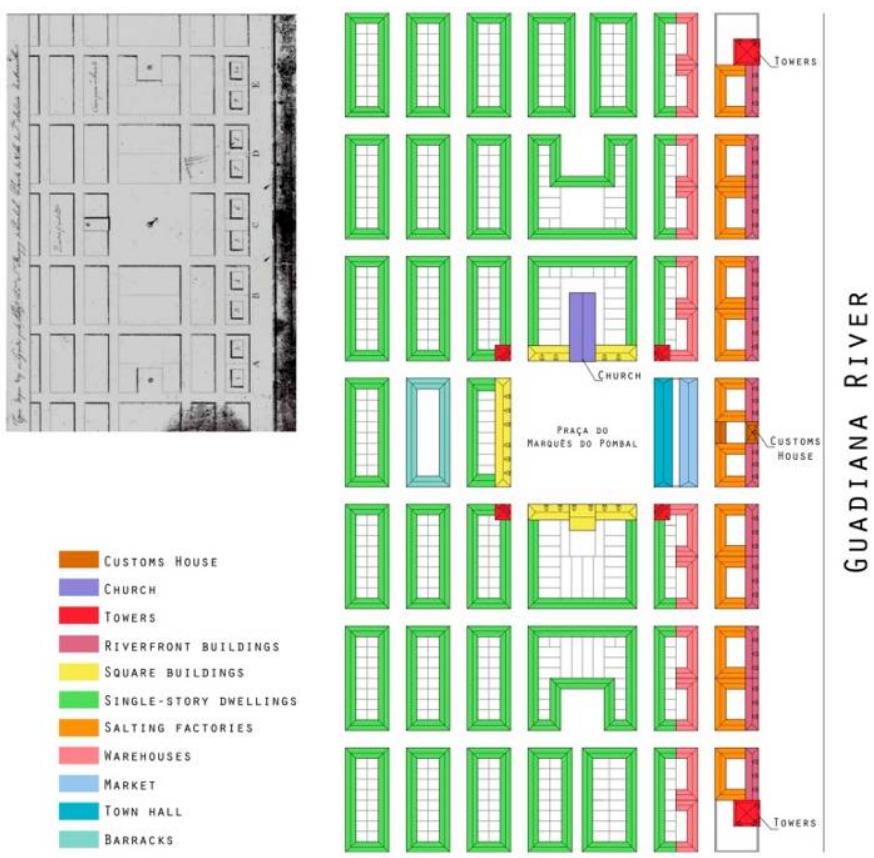

Figure 1. (left) First plan of the new city from 1774 (Correia 1997); (right) Original plan of Vila Real de Santo António and main architectural types (adapted from Rossa 2009).

At an architectural level, the most significant seismic resistant constructive solutions applied was the inclusion of timber frame partition frontal walls 
that connect the timber roof structure and the timber floor structure, analogous to the system developed for the reconstruction of Lisbon known as gaiola Pombalina. Given the low height of the buildings in Vila Real de Santo António, the use of the whole seismic resistant construction system was not necessary but these timber frame structural walls were used in those buildings with more than one floor and can still be observed in some of the buildings today (Figure 2). The seismic concern that emerged after the earthquake can also be perceived in the generalized good quality and strength of the original buildings of Vila Real de Santo António (Oliveira 2009). Stone was used for the load bearing exterior and party masonry walls, which are the main structural resisting element in all the buildings, and timber was used for the roof and floor structures, using prefabricated elements imported from Lisbon. Some ground floor rooms had vaulted ceilings supporting the first floor as a fire prevention measure, as occurred in Lisbon (Mascarenhas 1996).
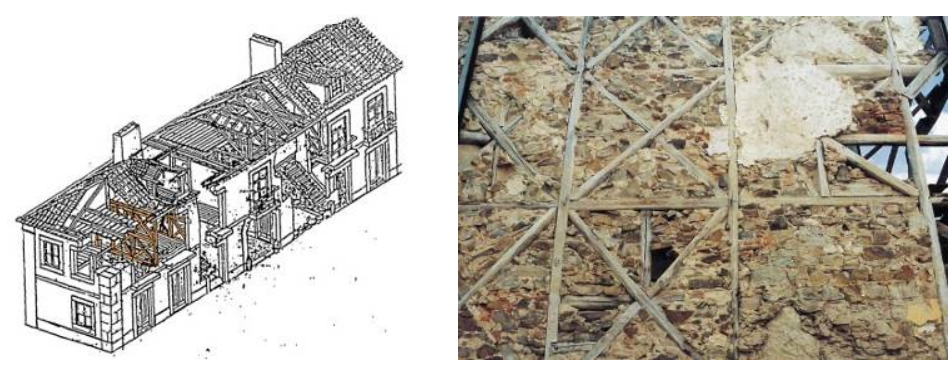

Figure 2. (left) Use of frontal walls in two-story buildings in Vila Real de Santo António (Mascarenhas 1996); (right) Frontal wall in Vila Real de Santo António (Figueiras 1999).

However, a part of the original buildings have nowadays either been substituted or are highly altered. Few buildings still preserve their original characteristics in terms of volume or elevation and even less maintain the original structural elements. Most of these alterations (addition of new floors, enlargement or addition of openings, substitution of floors and roofs, etc.) are a normal consequence resulting from the changes of the use of the buildings and the new needs of the users but the deep mischaracterization of the built-up environment also reveals a loss of seismic awareness, as the initially adopted effective seismic resistant measures were abandoned. A research question arises whether or not and to what extent these changes on the original constructions have compromised the seismic resistance of the buildings.

The Alfândega building (the old Customs House of the city) was constructed using traditional seismic resistant features and is one of the buildings that show nowadays less alterations, preserving most of the original structural elements. Therefore, it was selected as a representative example of the rest of the buildings of the city for a deeper study. This study is also based on the assumption that those buildings constructed after the earthquake were built in a workmanlike manner and can present far less vulnerability than expected, bearing important lessons on hazard mitigation. Consequently, two goals were finally set: (a) the understanding of the resisting mechanisms and seismic behavior of the building; and (b) the evaluation of the influence of structural alterations done over the years.

\section{DESCRIPTION OF THE $A L F \hat{A} N D E G A$ OR CUSTOMS HOUSE BUILDING}

\subsection{Historical survey}

The Alfândega building occupies a central position in the river front, which functions as a sort of façade for the city and as a display of political power (Correia 1997), facing the Spanish border, at the other side of the river. The building was enclosed within an urban block that also included two-story buildings facing the river, and single story salting factories, situated behind them, forming two patios with a U-shape plan configuration (Figure 3). The Alfândega building was originally composed by two independent two-story buildings. The main one was located at the riverside, aligned with the river front buildings, and had a timber frame mansard roof that rises up from the roof ridge line of the neighboring buildings. The other building was placed at the back of the block and was also higher than the adjacent single story salting factories. There was a third patio in the block in between these two buildings.

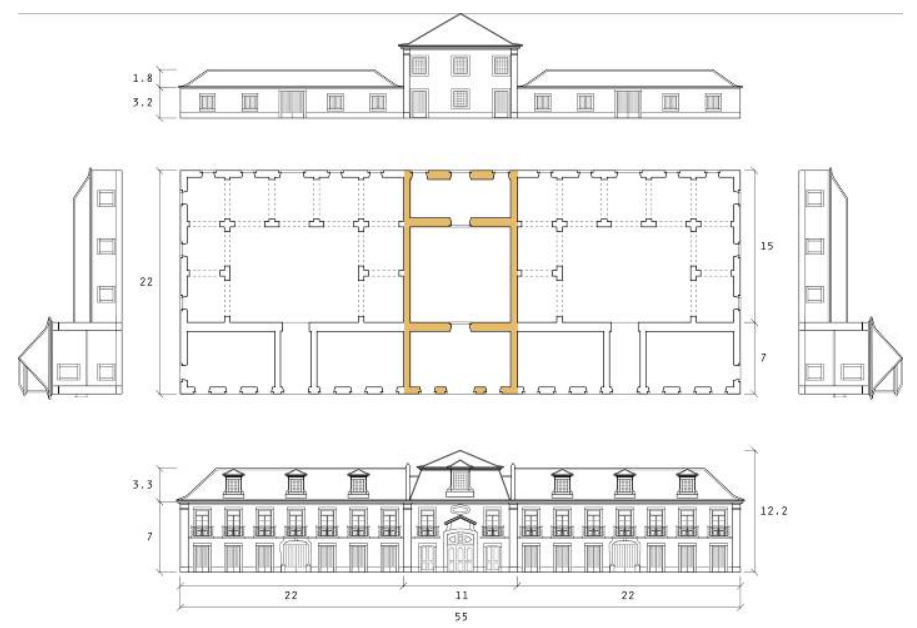

Figure 3. Original plans and elevations of the block. The Alfândega building is marked in orange (dimensions in meters).

In terms of construction, stone masonry walls and wooden floor slabs composed the basic and simple box-type structural scheme. The timber frame partition frontal walls were also present in the upper floors and had also a structural function because, by connecting the different structural elements, i.e. roof, floor and exterior masonry walls, they contrib- 
uted to the bracing of the building, improving its overall resistance. The partition walls at the ground floor level were heavier, built of solid brick masonry. The use of a lighter system in the upper level also ensured a better structural behavior by lowering the center of gravity of the building and thus provides greater stability.

\subsection{Current condition of the urban block}

The Alfândega building overall preserves most of its original characteristics but the rest of the constructions within the block have suffered important alterations. The salting factories were either replaced with new buildings or highly altered (mainly by addition of new floors), while the original patios were occupied by additional constructions. There were also many alterations in the façade, such as the enlargement of the openings, the opening of new ones and the closing of others. Figure 4 shows an axonometric comparison between the original and current condition of the block.

All these changes may have increased the seismic vulnerability of the building. First of all, the original compact regular and rectangular plan configurations that typically behave better under seismic loading are completely modified. The accumulation of buildings within the patio has introduced setbacks and irregularities that may introduce torsional effects in the seismic response of the whole block. The addition of new floors to the original constructions has led to a significant increase in the height of the building and to the presence of adjacent buildings with different heights. This type of modifications can also entail the presence of staggered floors among the buildings within the block, which can be detrimental for the seismic response by introducing risk of hammering, particularly dangerous if the floors have been substituted for rigid reinforced concrete floors. This is important, since buildings within urban blocks do not behave independently and the actions of adjacent buildings should be taken into account.

\subsection{Architectural survey}

The architectural survey allowed sketching the current plans of the building that will be used to prepare the numerical model, see Figure 5. The main alteration done in the building has been the occupation of the original patio and the construction of a much smaller courtyard. The building has still two welldifferentiated parts. The main façade body is mostly untouched and has two floors and an attic, while the rest of the building is composed only by the ground and the first floor. There are brick masonry arcades at the back part of the ground floor, which are in a good state of conservation (Figure 6). There is also a brick masonry barrel vault covering one of the small rooms attached to the courtyard at the ground floor (Figure 6). The staircase connecting the three floors is situated in the main building, with a direct access from the façade.

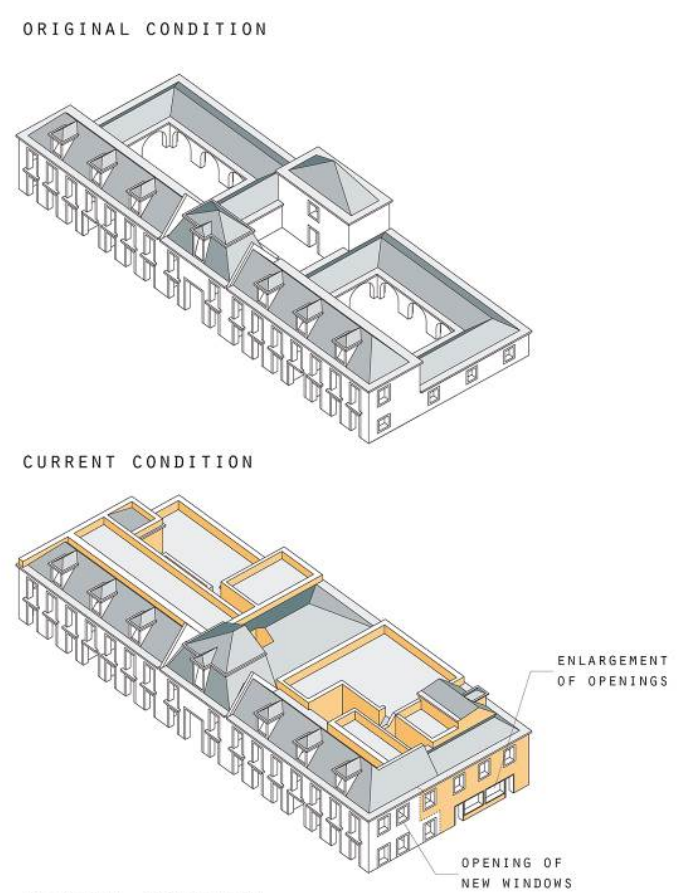

ORIGINAL CONDITION

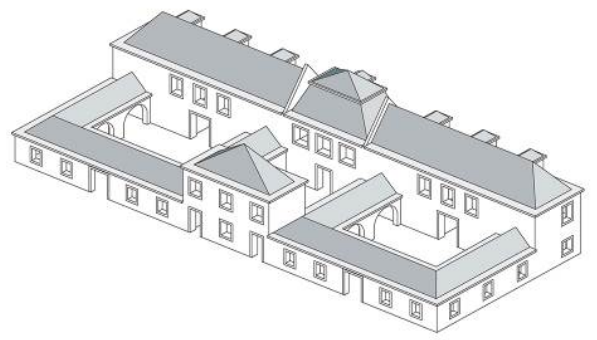

CURRENT CONDITION

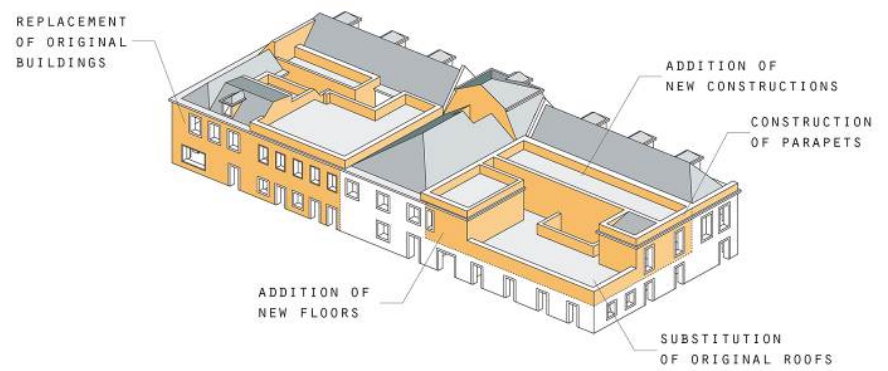

Figure 4. Comparison between original and current state of the Alfândega block. The alterations are highlighted in orange.

The first floor is more compartmentalized and the nonstructural light partition walls are made of different materials, some of them including timber frame structures showing different geometries (Figure 7). However, most of them do not seem to be original neither preserve their original structural bracing function. Another important alteration was the reconstruction of the mansard roof timber structure of the main building and the construction of a gable wall at the back part of the roof (Figure 8). 

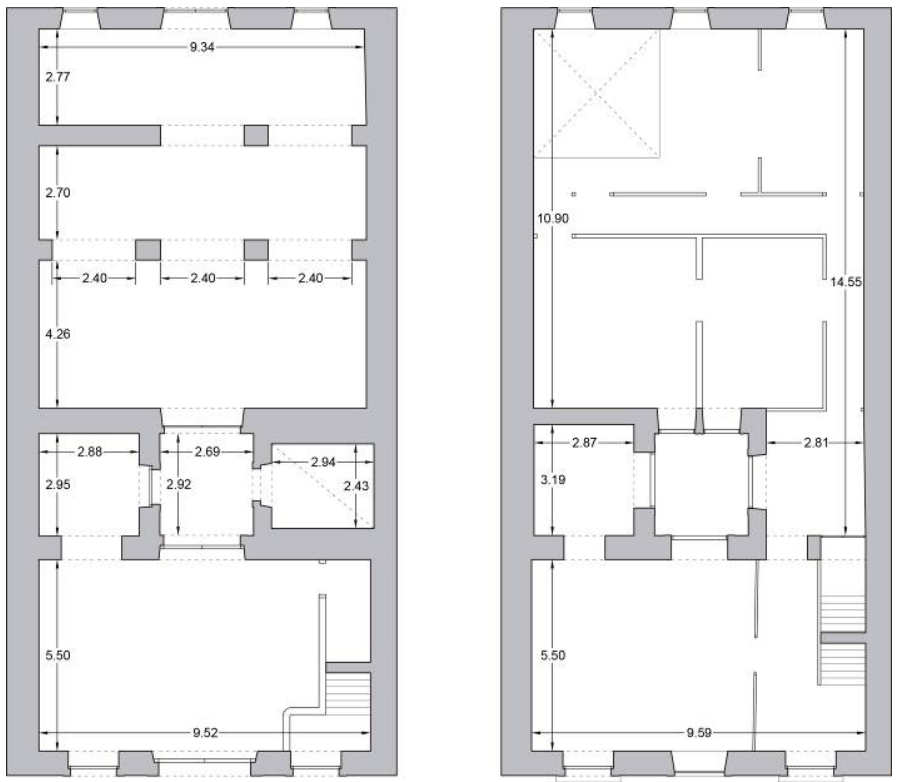

Figure 5. Current plans of the Alfândega building (left) Ground floor plan; (right) First floor plan (dimensions in meters).
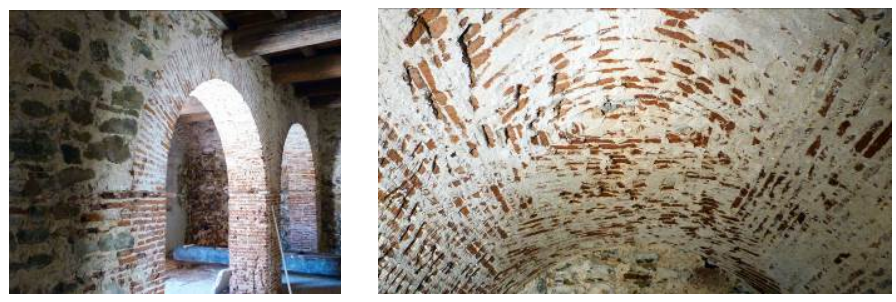

Figure 6. (left) Brick masonry arcades (right) brick masonry barrel vault.
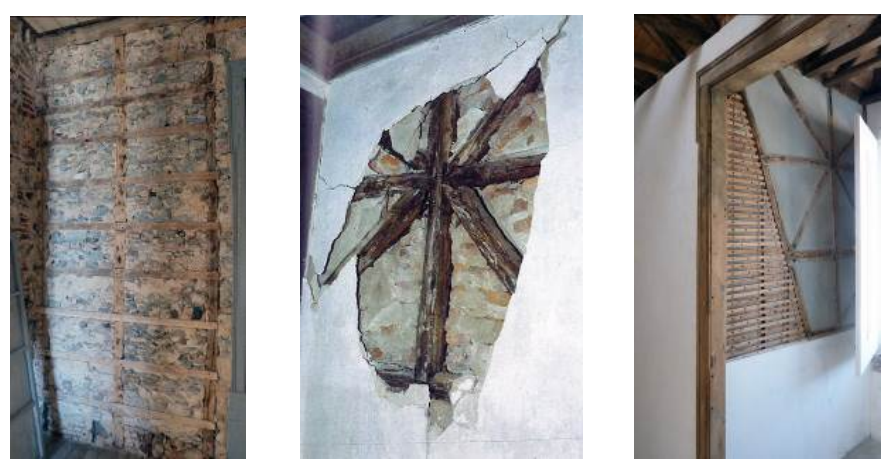

Figure 7. Different types of timber frame partition walls observed in the Alfândega building.
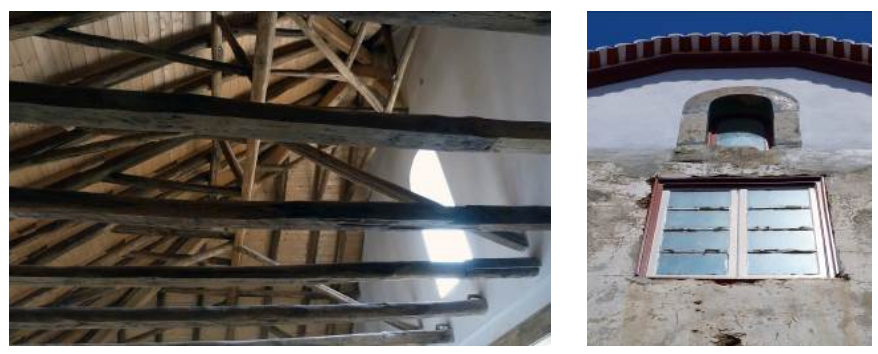

Figure 8. (left) Reconstructed timber mansard roof of the main building; (right) View from outside of the gable wall constructed at a later stage.

\subsection{Material survey}

Load-bearing stone masonry walls are the main structural element. Since the walls masonry was exposed at the time of the visit, we could observe that it is composed of highly irregular units in size and shape with not respected horizontal courses, bonded with mortar and with pieces of brick and rubble inserted within (Figure 9). The morphology of the cross section could not be verified but after what could be observed in other buildings in the city, is most likely composed of two leafs with rubble in between. The walls thickness can vary between 0.60 and $0.70 \mathrm{~m}$.

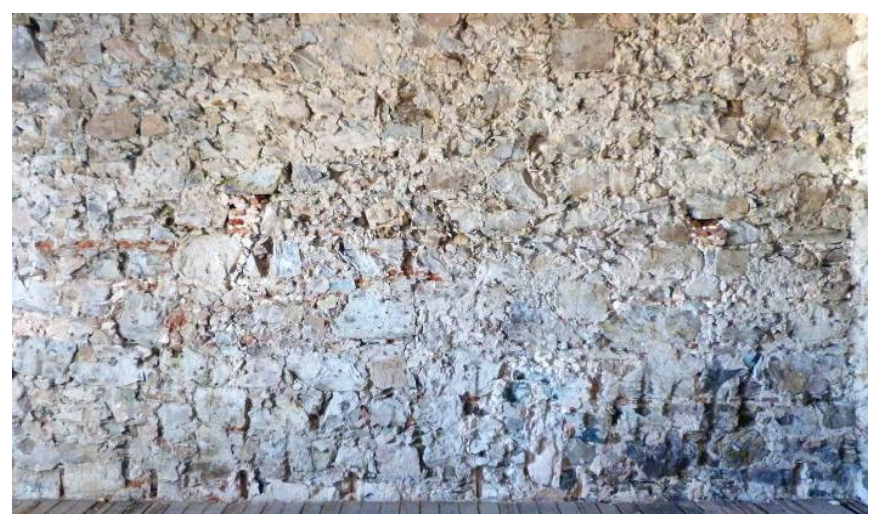

Figure 9. Stone masonry morphology.

The timber beams composing the floor structure have a variable cross section that can be circular or rectangular, with dimensions significantly varying from around 0.15 up to around $0.30 \mathrm{~m}$. diameter, and are in an overall good state of conservation. They are placed perpendicular to the façade and, in the main building, they rest on transverse timber plates, allowing a better distribution of stresses along the wall, while in the rest of the building, they pierce the stone masonry walls (Figure 10).
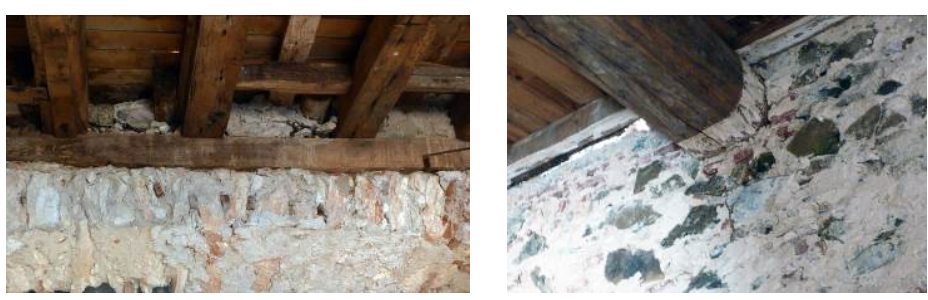

Figure 10. (left) Timber floor beams resting on transverse timber plate (right) Timber floor beams piercing the walls.

\section{DYNAMIC IDENTIFICATION}

In-situ dynamic identification was carried out aiming at estimating the natural frequencies and vibration modes of the building, which will be used to calibrate the numerical model. In the experimental modal analysis, six accelerometers were used and 
records were taken in 20 different points within five test setups, the layout of the sensors is shown in Figure 11. Two reference accelerometers were common in all the setups (marked in red in the figure). They were chosen to be placed at the top of the façade wall because the expected mode shapes to be captured mainly involve out-of-plane displacements of the façade and the two parallel walls. Therefore, most of the locations of measurement points are located in upper points of these three walls. Two points were chosen in the perpendicular direction in one of the patio walls, aiming at capturing other unexpected mode shapes.
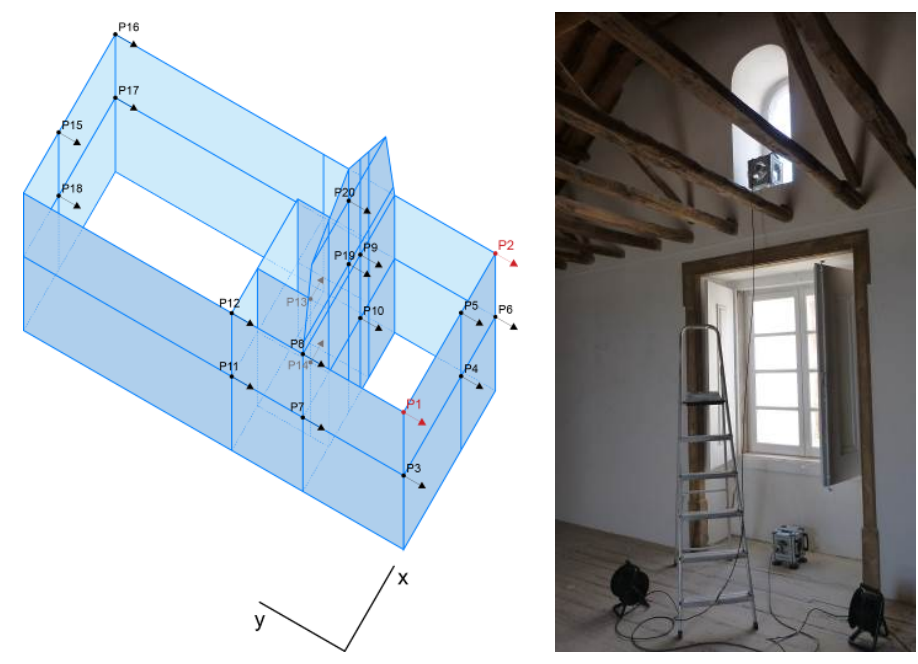

Figure 11. (left) Axonometric scheme of the location of the accelerometers; (right) Sensors.

The modal estimation was performed using two techniques in order to later compare the results using the Modal Assurance Criterion (MAC): (i) the Enhanced Frequency Domain Decomposition (EFDD) peak picking technique; and (ii) the Stochastic Subspace Identification - Unweighted Principal Components (SSI-UPC) technique, both of them available in ARTeMIS software (ARTeMIS 2015). Table 1 shows the first four vibration modes that could be clearly identified within a frequency range below 16 $\mathrm{Hz}$, and the error using the SSI-UPC method as a reference. The first two modes present MAC values close to one, which means a good match of both mode shape vectors, confirming the validity of the modes selected. The fourth mode also shows a high MAC value, which confirms that there is a transversal mode, involving the longitudinal wall.

Table 1. Estimated frequencies.

\begin{tabular}{lcccc}
\hline & \multicolumn{2}{c}{ FDD } & SSI-UPC & \\
\cline { 2 - 4 } & $\begin{array}{c}\text { Frequen- } \\
\text { cy (hz) }\end{array}$ & $\begin{array}{c}\text { Error } \\
(\%)\end{array}$ & $\begin{array}{c}\text { Frequen- } \\
\text { cy (hz) }\end{array}$ & MAC \\
\hline Mode 1 & 7.09 & +0.70 & 7.13 & 0.99 \\
Mode 2 & 10.97 & -0.09 & 10.96 & 0.79 \\
Mode 3 & 11.39 & +0.96 & 11.50 & 0.55 \\
Mode 4 & 14.02 & -0.50 & 13.95 & 0.87 \\
\hline
\end{tabular}

Figure 12 shows the first four identified modes in the longitudinal directions. The first mode consists of a longitudinal global mode in the direction perpendicular to the façade, being the taller middle walls the main contributor. With the exception of this clear out-of-plane first mode $(7.13 \mathrm{~Hz})$, the other obtained modes are a combination of local modes taking place in the different transversal walls and the frequency values were very similar, which made the identification of the modes difficult. The second mode involves mainly the façade and the third mode the back wall. The fourth mode is a global mode combination of a global transversal mode with torsion.
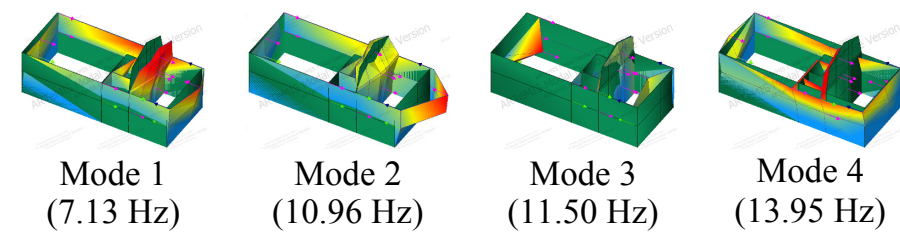

Figure 12 First four identified modes through the dynamic identification.

\section{REFERENCE MODEL}

The geometry of the reference model was obtained through the architectural survey carried out in-situ and available plans of the original Alfândega building. The first model was constructed with DIANA software (TNO 2009), using 3D CTE30 ten-node solid tetrahedron elements with a 4-point integration scheme over the volume. The elements have an average side of $0.25 \mathrm{~m}$. Four different materials were considered at the beginning: (a) good quality stone regular masonry for the walls; (b) brick masonry for the arches and ground floor vault; (c) coarse rubble masonry for the infill of the vault, which is assumed to be made by rubble because this is the common practice in historic buildings; and (d) reinforced concrete for some elements of the back wall, since it was partially reconstructed and the presence of RC elements such as lintels was confirmed during the visual inspection. Figure 13 shows the model initially constructed.

The roof and the floors were initially considered as distributed loads on top of the walls, since the modelling of the building without timber floors is a conservative approach (Ramos \& Lourenço 2004). However, after a first modal analysis, it was noticed that they seem to highly contribute to the structural behavior of the building because, if not considered, the walls behave independently and local modes were obtained, while the modes obtained through the experimental dynamic identification were global. Additionally, after visual inspection, a rather overall good condition and a significant dimension of the timber floor beams was noticed (Figure 10). 

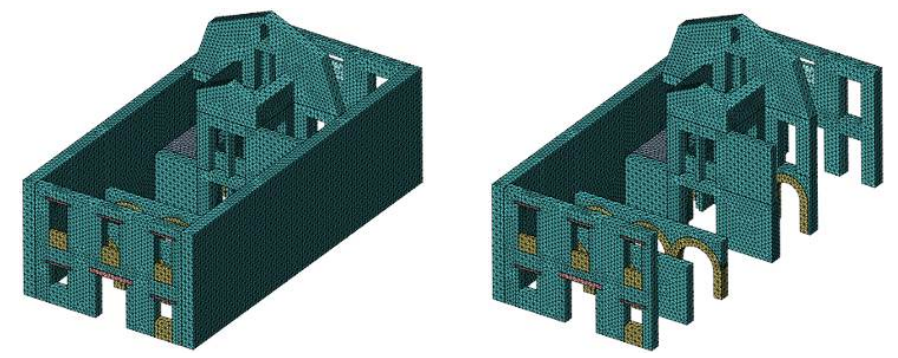

Figure 13. Different views of the first model considered.

Therefore, the coupling action of the floors was taken into account and the beams were modelled as two-node translation SP2TR springs, assuming perfect linear elastic behavior and computing the axial stiffness as $\mathrm{K}=\mathrm{EA} / \mathrm{L}$, where $\mathrm{E}$ is the modulus of elasticity considered for the beam, $\mathrm{A}$ is the area of the cross section and $\mathrm{L}$ is the length. Distributed loads were still kept for their weight. The mansard roof, even though it presents also an overall good condition because it was reconstructed, was still simply considered as equivalent static loads because, due to its complex geometry, the possible tying effect did not seem to be taking place.

The influence of the adjacent buildings that confine the Alfândega was initially simulated by constructing the two existing longitudinal walls and restraining their movement in the $\mathrm{X}$ direction (Figure 13). Nevertheless, these two longitudinal walls were finally not modeled because of two reasons: (i) the thickness of the walls is unknown; and (ii) the level of connection between perpendicular walls was also unknown and could vary from wall to wall, since, for example, part of the back wall was reconstructed at the connection between the walls (Figure 14). In addition, the modelling of the longitudinal walls involved the addition of many elements which are not very significant in the global structural behavior and highly increased the computing time. The effect of the longitudinal walls was instead simulated by restraining the movement in the $\mathrm{X}$ direction at the connections and using one-node translation springs to restrain their movement in the Y direction. Linear elastic springs were also considered because it was assumed that these longitudinal walls were not going to fail in their in-plane direction.

The displacement of all the elements is fully restrained at their base. The final resulting generated mesh has 146,137 nodes and 84,998 elements (see Figure 15). The total mass of the model is 425 tons. A total strain rotating crack model was selected to simulate the nonlinear behavior of all the masonry types. This model follows a smeared approach for the fracture energy and assumes that the crack direction rotates with the principal strain axes (TNO 2009). It has been widely applied to model complex historical masonry structures because it is very well suited for analyses predominantly governed by cracking or crushing of the material. It describes the tensile and compressive behavior of the material with one stress-strain relationship. The tension softening function selected is exponential and the compressive function selected is parabolic.
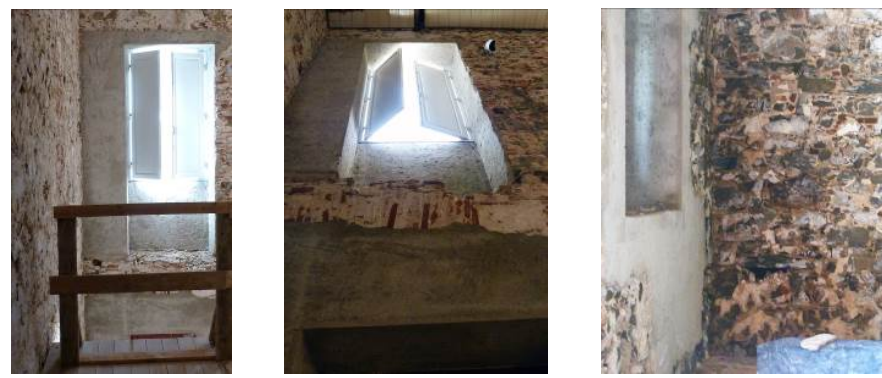

Figure 14. Different parts of the back wall partially reconstructed close to the connection with the longitudinal walls.
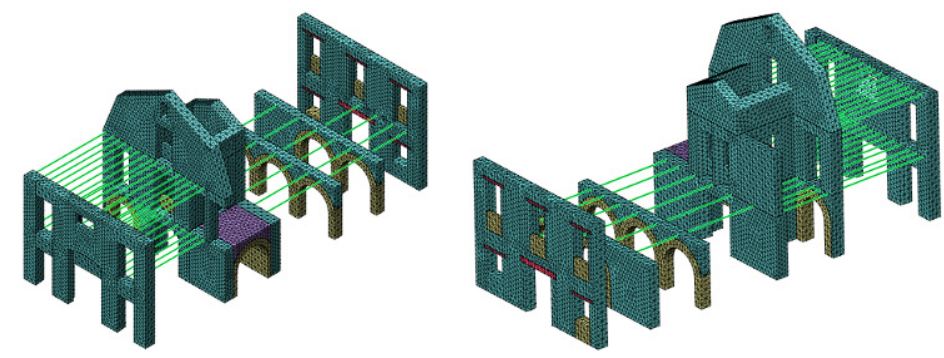

Figure 15. Different views of the final model.

Only the masonry is considered to present nonlinear behavior since the structural nonlinearities are expected to concentrate there. The elastic properties adopted for the different materials: elasticity modulus (E), Poisson's ratio (v) and weight (W); are shown in Table 2 . The masonry nonlinear properties required to define the material model adopted are shown in Table 3 . The compressive strength $\left(f_{c}\right)$ is obtained from common values observed in the literature and the remaining properties are computed directly from the compressive strength. The compressive fracture energy $\left(\mathrm{G}_{\mathrm{fc}}\right)$ is obtained using a ductility factor $\mathrm{d}$ of $1.6 \mathrm{~mm}$, which is the ratio between the fracture energy and the ultimate compressive strength. The tensile strength is estimated at $0.1 \mathrm{f}_{\mathrm{c}}$. Finally, an average value of $0.012 \mathrm{~N} / \mathrm{mm}$ is adopted for the mode I fracture energy $\left(\mathrm{G}_{\mathrm{fI}}\right)$.

Table 2. Mechanical elastic properties adopted.

\begin{tabular}{lccc}
\hline & $\begin{array}{c}\text { E } \\
\text { Material }\end{array}$ & $v$ & $\begin{array}{c}\text { W } \\
(\mathrm{MNa})\end{array}$ \\
\hline Stone masonry & 2000 & 0.2 & 20 \\
Brick masonry & 3600 & 0.2 & 18 \\
Infill masonry & 300 & 0.2 & 20 \\
Reinforced concrete & 26000 & 0.2 & 24 \\
\hline
\end{tabular}

Table 3. Mechanical nonlinear properties adopted.

\begin{tabular}{lcccc}
\hline Material & $\begin{array}{c}\mathrm{f}_{\mathrm{c}} \\
(\mathrm{MPa})\end{array}$ & $\begin{array}{c}\mathrm{G}_{\mathrm{fc}} \\
(\mathrm{MPa})\end{array}$ & $\begin{array}{c}\mathrm{f}_{\mathrm{t}} \\
(\mathrm{MPa})\end{array}$ & $\begin{array}{c}\mathrm{G}_{\mathrm{fI}} \\
(\mathrm{N} / \mathrm{mm})\end{array}$ \\
\hline Stone masonry & 2.0 & 3.2 & 0.2 & 0.012 \\
Brick masonry & 3.6 & 5.76 & 0.36 & 0.012 \\
Infill masonry & 1.0 & 1.6 & 0.1 & 0.012 \\
\hline
\end{tabular}




\section{MODEL CALIBRATION}

In order to assess if the finite element model simulates correctly the structural behavior of the building, its dynamic characteristics can be compared with the experimental ones. Three parameters were chosen for the calibration of the model: (i) the level of connection granted by the floor timber beams, which seem to have a large influence in the global structural behavior; (ii) the modulus of elasticity of the different masonry walls, as they seem to have been built at different times and have different properties; and (iii) the level of connection and stiffness of the longitudinal wall.

Thus, three different wall types were considered depending on their construction time: (a) the façade wall and the first two floors of the parallel wall, which compose the original main body of the XVIII century building; (b) the rest of the walls composing the courtyard and the top gable middle taller wall, which are an addition to the original building; (c) the back wall, which was also built at a later stage and, furthermore, RC elements have been introduced, such as lintel openings, and partial reconstructions of the wall with better quality and regular masonry took place, which was confirmed with the in-situ visit.

The calibration thus consisted of increasing the modulus of elasticity of the courtyard wall and the back wall masonries, and varying the stiffness of both the springs simulating the floor timber beams of the front body and the springs simulating the longitudinal wall. The modes were compared with the experimental results in terms of MAC values and the results are shown in Table 4. It is noted that only the first three modes were compared. The optimized model, in comparison to the experimental values, has an average frequency error lower than $0.1 \%$ and an average MAC of 0.83 which is rather satisfactory value. Table 4 presents also the modes and frequency values obtained with the FE model, which replicates quite satisfactorily the experimental modes.

The satisfactory values obtained for all the three mode shapes confirm the two main hypothesis taken into account: (1) the floor timber beams have an important influence in the global behavior and couple the parallel walls to certain extent, confirming the good quality of the original construction; and (2) the walls have different properties because of having been constructed at different times. The original elastic modulus considered for the original walls masonry is kept as $2 \mathrm{GPa}$, the modulus of elasticity of the courtyard walls and the top gable wall was updated to $3.6 \mathrm{GPa}$, and the modulus of elasticity of the back wall equals to $6 \mathrm{GPa}$. The high modulus of elasticity obtained for this wall's masonry can only be justified because of the significant presence of $\mathrm{RC}$ elements.
Table 4. Dynamic calibration results and comparison between the numerical and experimental modes.

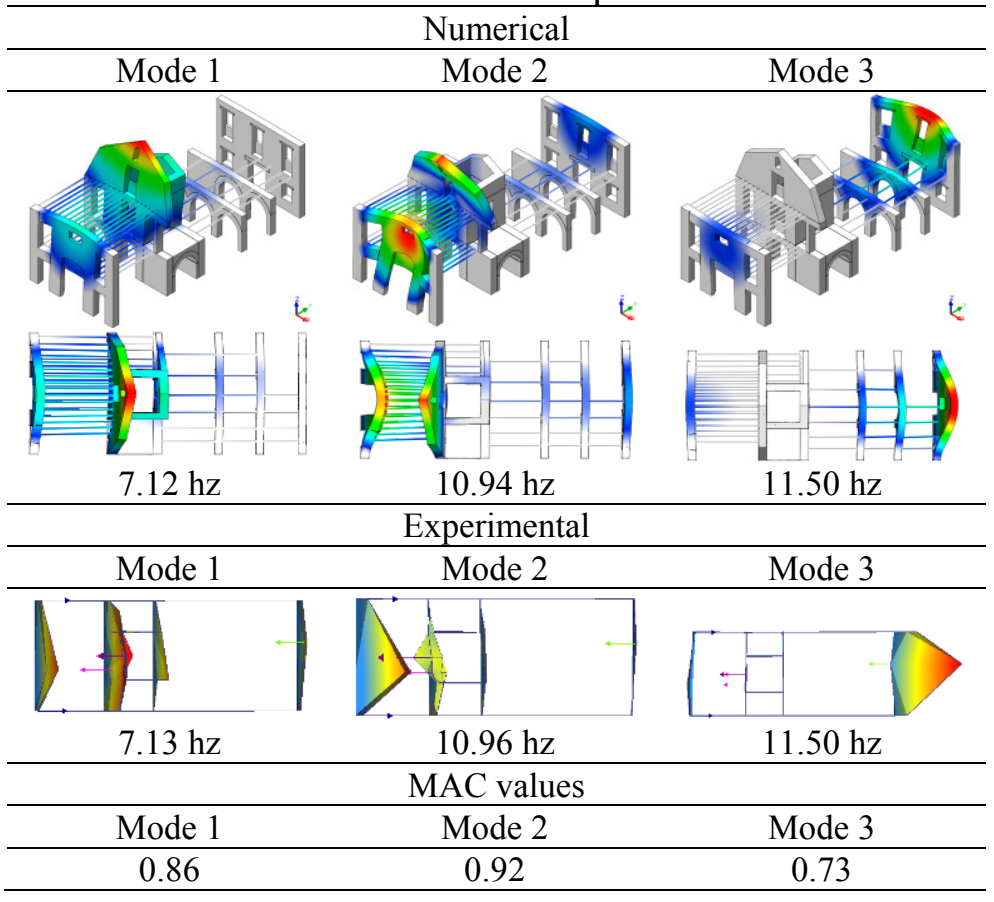

\section{STRUCTURAL ANALYSIS}

Pushover analyses proportional to the mass were also performed in order to assess the seismic response of the building, applying increments of the load in + and $-Y$ directions. The perpendicular direction was disregarded because of the presence of buildings at both sides. Figure 16 depicts the capacity curves for both directions for a point on top of the gable wall and Figure 17 shows the maximum tensile strains, which can be directly correlated with the damage.

The maximum load coefficient obtained in the $+Y$ direction is $0.28 \mathrm{~g}$ and the failure mode consists of the out-of-plane rotation of one of the walls composing the courtyard. This failure is accelerated by the presence of big openings in the courtyard walls, which enhance their in-plane failure. As it could be expected, there is also important damage taken place at the connection of the transversal walls with the longitudinal one. Almost all the damage concentrates in the walls around the courtyard, except from some minor damage at the connections between the façade and the back wall with the longitudinal walls.

The pushover analysis in $-\mathrm{Y}$ direction reaches a maximum load coefficient of $0.25 \mathrm{~g}$. The lower capacity and higher deformation can be explained because the taller gable wall now rotates more freely, and the failure mode occurs because of out-of-plane rotation of this element. The horizontal crack that is also needed for the formation of this type of local mechanism can be clearly observed (Figure 17). This is a common failure mode of buildings that present gable walls, which are particularly vulnerable to seismic actions. Most of the damage concentrates at the connection with the perpendicular courtyard 
walls, showing the separation between them. There is also damage at the connection of the gable wall with the longitudinal wall.

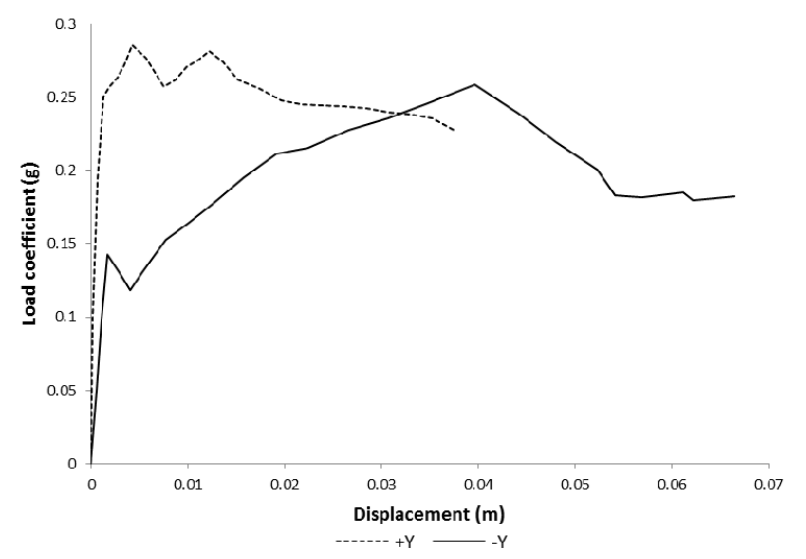

Figure 16. Capacity curves of the pushover analysis in + and $\mathrm{Y}$ directions.
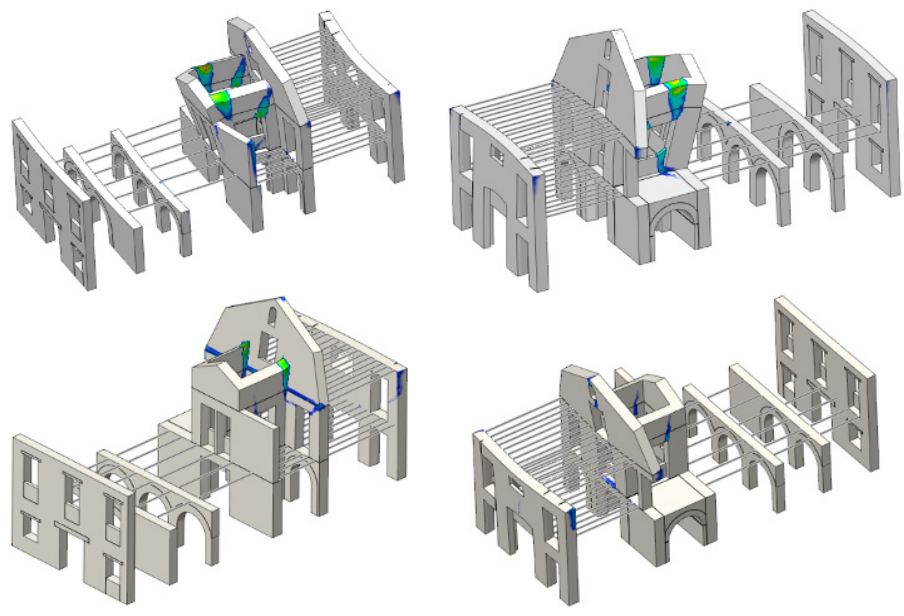

Figure 17. Maximum principal strains (a cracking measure) at peak load: (top) in $+Y$ direction; (bottom) in $-Y$ direction.

Again, the courtyard walls present widespread damage, revealing their in-plane failure, where cracks always arise from the opening edges. The cracks that occur at the top window of the tympanum and another crack developing at the middle part of the façade wall show also flexural bending failure taking place in both walls. This time, the façade wall shows more extended damage at the connection with the longitudinal wall.

\section{CONCLUSIONS}

The seismic behavior Alfândega building in Vila Real de Santo António has been thoroughly studied through experimental and numerical methods. Both techniques have been applied as complementary tools for a better understanding of the resisting mechanisms of the building to horizontal loading and for the evaluation of the influence of structural alterations done in the building, since the dynamic identification allowed the calibration and validation of the numerical model.

Both failures obtained in the numerical analysis take place in structural elements that were not original, showing how the structural alterations made in the building have actually jeopardized the seismic safety of the building. Vila Real de Santo António thus exemplifies how the loss of the seismic awareness has led to the abandonment of Local Seismic Cultures and the initially adopted seismic resistant measures. The original concern that arose after the 1755 earthquake resulted in an effective urban plan and carefully constructed architecture, but was eventually forgotten and compromised. The re-adoption of some of the traditional strengthening techniques originally developed can help in reducing this regained seismic vulnerability.

\section{ACKNOWLEDGEMENTS}

The work presented in this paper was supported financially by the research project Seismic V - Vernacular Seismic Culture in Portugal (PTDC/ATPAQI/3934/2012 funded by the National Foundation for Science and Technology.

\section{REFERENCES}

ARTeMIS Modal. 2015. Structural Vibration Solutions A/S. Release 4.0.0.6. -x86. Denmark.

Correia, J. 1997. Vila Real de Santo António. Urbanismo e Poder na Política Pombalina. PhD Thesis, Faculdade de Arquitectura da Universidade do Porto, Portugal.

Correia, M., Carlos, G., Rocha, S., Lourenço, P.B., Vasconcelos, G. \& Varum, H. 2014. SEISMIC-V: Vernacular seismic culture in Portugal. In M. Correia, G. Carlos \& S. Rocha (eds), Vernacular Heritage and Earthen Architecture: Contributions for Sustainable Development: 663-668. London: Taylor \& Francis Group.

Ferrigni, F. (ed.) 1990. À la recherché des anomalies qui protégent. Actes des Ateliers Européens de Ravello, 19-27 Novembre 1987. Ravello: PACT Volcanologie et Archéologie \& Conseil de L'Europe.

Figueiras, R. 1999. Vila Pombalina. Vila Real de Santo António. Vila Real de Santo António: Câmara Municipal Vila Real de Santo António.

Mascarenhas, J.M.D. 1996. A study of the design and construction of buildings in the Pombaline quarter. $\mathrm{PhD}$ Thesis, University of Glamorgan, UK.

Oliveira, A. 2009. Casa da Câmara de Vila Real de Santo António. Levantamento arqueológico. Monumentos 30: 54-61.

Ramos, L.F. \& Lourenço, P.B. 2004. Modeling and vulnerability of historical city centers in seismic areas: a case study in Lisbon. Engineering Structures 26(9): 1295-1310.

Rossa, W. 2009. Cidades da razão: Vila Real de Santo António e arredores. Monumentos 30: 16-31.

TNO. 2009. DIsplacement method ANAlyser (DIANA) user's manual. Release 9.4.4. Netherlands. 